IX.

\title{
Ueber die Vermeidbarkeit der Infiltrationsbildung bei der Mäusetyphusvaccination gegen Hogcholera durch Verwendung von sensibilisirtem Antigen.
}

Von

\author{
Dr. Julius Citron,
}

Assistenten der II. med. Klinik zu Berlin, frïherem Assistenten am Königl. Institut f. Infectionskrankheiten.

Die zu besprechenden Versuche wurden von mir im Jahre $1905 \mathrm{im}$ Wassermann'schen Laboratorium des Königl. Instituts für Infectionskrankheiten ausgeführt, in der Absicht, ein für die Praxis brauchbares Impfschutzverfahren gegen die Schweinepest zu sehaffen. Da durch die Untersuchungen von Dorset, Bolton und $\mathrm{Me}$. Bryde die ätiologische Bedeutung der Hogcholerabacillen für die Schweinepest bald darauf schwer erschüttert wurde, verloren diese Versuche das practische Interesse, das ihnen sonst zugekommen wäre. Mein Ausscheiden aus den Diensten des Königl. Instituts für Infectionskrankheiten verhinderte dann die Fortführung der Versuche, die aus theoretischen Gründen wünschenswerth gewesen wäre. Und so unterblieb bisher die Publication. Arbeiten auf einem anderen Gebiete der Immunitätsforschung, mit denen ich zur Zeit beschäftigt bin, und Beobachtungen, die ich dabei machen konnte, lassen es mir nun gegenwärtig wünschenswerth erscheinen, die folgenden Versuchsresultate zu veröffentlichen. Für die Erlaubniss hierzu spreche ich Hern Geh.-Rath A. Wassermann meinen verbindlichsten Dank aus.

Die Immunisirung von Kaninchen gegen die lebenden, vollvirulenten Hogcholerabacillen ist eine der schwierigsten Aufgaben der Immunitätsforschung. Die Vorbehandlung mit abgetödteten Hogcholerabacillen führt nicht zum Ziel. Wohl gelingt es so relativ leicht, Antikörper der verschiedensten Art, insbesondere Agglutinine, zu erzeugen, aber die Thiere erliegen der Infection mit lebenden, vollvirulenten Bakterien, ebenso wio nichtimmunisirte Controlthiere. Ein Immunisirung mit lebenden virulenten Bacillen ist unmöglich, weil Kaninchen derartige Infectionen selbst mit kleinsten Dosen in der Regel nicht überstehen. Mit Aggressinen und Extracten aus lebenden und virulenten Bacillen kann man, wie ich (1) früher zeigen konnte, wohl bei Kaninchen einen Impfschutz erzielen, allein die so erreichbare Immunität ist unzuverlässig.

Die einzige Methode, mit der es gelingt, Kaninchen gegen die intra- 
venöse, d. h. schwerste Infection mit lebenden, vollviruleriten Hogcholerabacillen zu immunisiren, ist die Vaccination mit Mäusetyphusbacillen, wie sie von Wassermann, Ostertag und mir (2) empfohlen wurde. Ein jedes Kaninchen, das in dieser Weise immunisirt wurde, widerstand der späteren Infection erfolgreich. Diese Immunität äussert sich nicht in einem hohen Antikörpergehalt im Serum, sie ist jm Wesentlichen histogen.

War somit das Princip für eine zuverlässige Immunisirungsmethode gegen Hogcholera gefunden, so stellte sich doch der practischen Ausführung das Hinderniss in den Weg, dass die Kaninchen die Vorbehandlung mit Mäusetyphus im Allgemeinen schlecht vertrugen. Bei der subcutanen Injection kleiner Mengen lebender Mäusetyphusbacillen entstanden starke Infiltrationen, die zu Abscessen führen können. Manche Thiere werden auch kachektisch und gehen ein.

Bei den meisten Thieren freilich bilden sich die Infiltrate zurück und dann sind sie oft schon gegen Schweinepest immun. Absolut sichere Resultate erzielt man, wenn man zuerst subeutan und dann nach Verschwinden des Infiltrats intravenös ein zweites Mal mit Mäusetyphus implt.

Für die Brauchbarkeit unserer Vaccinationsmethode war es also von grösster Wichtigkeit, Mittel und Wege zu finden, um bei der Mäusetyphusvaccination die Bildung starker Infiltrationen mit allen ihren Folgeerscheinungen zu vermeiden. Mit dieser Aufgabe wurden von Herrn Geh.-Rath A. Wassermann seiner Zeit zugleich Herr Dr. C. Bruck und ich betraut. Wir führten unsere Untersuchungen vollständig unabhängig von cinander aus. Während Bruck versuchte, durch Zusatz von Desinficientien und durch Temperatureinflüsse das Mäusetyphusvaccin in geeigneter Weise abzuschwächen und schliesslich zu dem Resultat kam, dass auf diesen Wegen das erwünschte Ziel sich nicht erreichen liess, gelang es mir nach Ueberwindung zahlreicher Sehwierigkeiten endlich, in der Sensibilisirung eine ausgezeichnete Methode zu finden, um die Infiltratbildung a uf ein Minimum zu reduciren.

Es ist dies um so bemerkenswerther, als ich (3) zugleich fand, dass die Hogcholera- und Mäusetyphusbacillen anscheinend ein ausserordentlich geringes Bindungsvermögen für die Serumantikörper besitzen. So konnte ich zeigen, dass der Agglutinations- und Bakteriolysintiter von Schweinepestsera selbst nach langer Bindung mit Mäusetyphus- und Schweinepestbacillen meist keine merkliche Abnahme wahrnehmen liess. Um nun festzustellen, ob überhaupt eine Bindung von Immunkörpern an die Schweinepestbacillen erfolgt, prüfte ich die Infectionstüchtigkeit sensibilisirter Schweinepestbacillen im Meerschweinchenversuch. Zur Illustrirung möchte ich folgenden Versuch wiedergeben:

\section{Versuch XVI.}

$8 \mathrm{ccm}$ polyvalenten Schweinepestserums ( $1 / 10$ Bouillonverdünnung) werden mit 4 Oesen Schweinepest S versetzt. $1 / 2$ Stunde Brutschrankbindung. Dann $2 \mathrm{mal}$ in Bouillon gewaschen. Hierauf werden die Bakterien mit $6 \mathrm{ccm}$ Bouillon aufgeschwemmt. Dann ist in $1 \mathrm{ccm}$ der 
Aufschwemmung (mit Berücksichtigung des Materialverlustes) ungefähr $1 / 2$ Oese Cultur enthalten. Hierauf wird folgender Versuch angestellt: Cultur.

a) Intraperitoneale Injection von $1 \mathrm{ccm}(=1 / 2$ Oese $)$ gebundener

b) Intraperitoneale Injection von $1 / 2 \mathrm{ccm}(=1 / 4$ Oese $)$ gebundener Cultur $+1 / 2$ cem $(=1 / 4$ Oese $)$ frischer Cultur.

c) Intraperitoneale Injection von $1 \mathrm{ccm}(=1 / 2$ Oese $)$ frischer Cultur.

\begin{tabular}{|c|c|c|c|c|c|}
\hline des $\begin{array}{l}\text { No. } \\
\text { Thieres }\end{array}$ & Datum & Frische Cultur & Gebundene Cultur & $\begin{array}{l}\text { Nach } \\
24 \text { Std. }\end{array}$ & $\begin{array}{l}\text { Weiterer } \\
\text { Verlauf }\end{array}$ \\
\hline $\begin{array}{l}\text { 1. Meersehw. } \\
2 . \quad " \quad " \\
3 . \quad " \\
4 . \\
5 .\end{array}$ & $\begin{array}{c}27.3 .05 \\
" \\
" \\
"\end{array}$ & $\begin{array}{c}1 / 2 \text { Oese Schwp.-S. } \\
- \\
-\overline{-} \\
1 / 4 \text { Oese Schwp.-S. } \\
1 / 4 " \# \quad "\end{array}$ & 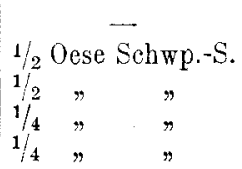 & $\begin{array}{c}\dagger \\
\text { krank } \\
\text { munter } \\
\dagger \\
\text { krank }\end{array}$ & $\begin{array}{l}\dagger \text { nach } 4 \mathrm{Tg} \\
+\Rightarrow 4 \% \\
+ \text { nach } 2 \mathrm{Tg}\end{array}$ \\
\hline
\end{tabular}

Das Ergebniss dieses Versuches ist klar, es findet eine Bindung von Immunkörpern statt, die freilich im Vergleich zu analogen Versuchen bei Typhus oder Cholera quantitativ recht gering ist.

Diese Versuche brachten mich auf den Gedanken, zur Vaccinirung der Kaninchen auch mit Antikörpern beladene (sensibilisirte) Bakterien zu versuchen.

Als Serum verwendete ich hierbei vor Allem Kaninchenimmunsera, die ich durch Immunisirung mit lebenden Mäusetyphusbacillen oder mit künstlichen Aggressinen von Hogcholerabacillen gewonnen hatte und die bei ihrer Auswerthung im Meerschweinchen- und Mäuseversuch hohen Schutzwerth (Titer $1 / 3000-1 / 5000$ ) gezeigt hatten. Da ich auf Grund meiner Bindungsversuche annehmen musste, dass die Sensibilisirung langsam und schwierig erfolgen würde, so verfuhr ich so, dass ich kleine Mengen Bakterien mit grossen Dosen unverdünnten Serums ( 1 Oese auf I ccm Serum) versetzte, dann das Gemisch erst 1-2 Stunden in den Brutschrank und hierauf für 24 Stunden in den Eisschrank brachte. Dann wurden die Bakterien abcentrifugirt und von Nenem in gleicher Weise mit frischem Serum gemischt und für 48 Stunden in den Eisschrank gebracht. Hierauf wurden die Bakterien in der elektrischen Centrifuge von dem Serum getrennt und in Bouillon aufgeschwemmt zur Impfung verwendet. Dieses Verfahren wurde dann von mir in der allerverschiedensten Weise modificirt, so dass de fecto jeder Versuch beinahe in anderer Weise unternommen wurde. Ich sehe jedoch von der detaillirten Wiedergabe der Protokolle hier ab, da nur das Princip selbst von Belang ist.

Gleich die ersten mit einem derartigen sensibilisirten Vaccin angestellten Versuche lehrten in zweifelloser Weise, dass mit der Sensibilisirung ein Weg zur Vermeidung von Infiltraten bei der Schutzimpfung gefunden war. Fast reactionslos wurde die subcutane Injection von den Kaninchen vertragen. Ausnahmsweise kam es zu ganz unbedeutenden kleinen Infiltraten, die in kurzer Zeit spontan verschwanden. Auch die intravenöse Injection wurde ausgezeichnet. vertragen und gab immunisatorisch sogar bessere Resultate. 
Die Sensibilisirung konnte noch verstärkt werden dadurch, dass zugleich mit den Bakterien Immunserum injicirt wurde.

Dass der Impfschutz durch die Sensibilisirung des Antigens nieht beseitigt wurde, liess sich leicht nachweisen. Das Schema, das sich mir am meisten bewährte, war folgendes:

1. Injection. 1/5-1/10 Oese sensibilis. Mäusetyphusvaccin $+1 \mathrm{ccm}$ Mäusetyphus- oder Hogcholeraserum subcutan oder intravenös.

2. Injection (8 Tage später). 1/10 Oese nichtsensibilis. Mäusetyphusvaccin intravenös oder $1 / 3$ Oese 24 stünd. Mäusetyphusbouillon subcutan.

Nach 10 Tagen waren die Thiere immun, wie sich durch intravenöse Infection mit $1 / 10$ Oese virulenter Schweinepest feststellen liess.

War somit das Princip für die Beseitigung der Infiltrationsbildung von mir gefunden, so war das Verfahren doch noch unbequem. Eine wesentliche Vereinfachung wurde schliesslich dadurch erzielt, dass es Herrn Geh.-Rath Wassermann gelang, durch monatelange Züchtung eines Bakterienstammes in einem Immunserum eine Cultur zu gewinnen, die die Eigenschaft erworben hatte, nur geringe Infiltrationen zu erzeugen.

Diese umgezüchtete Cultur wurde vollständig unschädlich, wenn man zu gleicher Zeit mit der Impfung eine Injection von Schweinepestoder Mäusetyphusserum gab. Hierzu liess sich das fabrikmässig hergestellte Schweinepestserum von Wassermann und Ostertag gut verwenden.

Wollen wir die Wirkung der Sensibilisirung verstehen, so müssen wir uns zunächst fragen, welche Substanzen des Schweinepestbacillus die Ursache der Infiltrationsbildung sind. Sind es die Bacillenleiber selbst oder in ihnen befindliche lösliche Substanzen? Ich (1) habe diese Frage bereits gelegentlich meiner Aggressinversuche dahin beantworten können, dass es nicht die Bakterienleibessubstanz an sich sein kann. Denn extrahirt man nach der zur Herstellung von künstlichen Aggressinen üblichen Weise die lebenden Bakterien, dann haben die ausgelaugten Bakterien neben ihrer immunisirenden Substanz auch die Fähigkeit, Infiltrate zu bilden, zunächst verloren. Erst nach einigen Tagen, wenn neue Bacillengenerationen entstanden sind, fängt auch die Infiltratbildung an. Tödtet man jedoch durch Hitzewirkung die ausgelaugten Bakterien erst $a b$, sodass sie sich nicht weiter vermehren können, dann bleibt jede Infiltrationsbildung aus, während in gleicher Weise abgetödtete nicht ausgelaugte Bakterien mächtige Infiltrationen veranlassen.

Es gehören also die infiltrationsbildenden Substanzen ebenso wie die immunisirenden zu den löslichen. Es bleibt die Frage, ob beide identisch sind. Es könnte scheinen, als ob sich dies mit Sicherheit ausschliessen liesse, weil sonst ja mit der erfolgreichen Neutralisirung der infiltrationsbildenden Substanzen eine Neutralisirung der immunisirenden erfolgen und damit ein Ausbleiben der Schutzwirkung eintreten müsste, was jedoch de facto, wie meine Versuche zeigen, nicht der Fall ist.

Trotzdem lässt sich diese Frage in so einfacher Weise zur Zeit nicht beantworten. Ist es doch seit langem bekannt, dass man durch 
158 J. Citron, Vermeidbarkeit d.Infiltrationsbild. bei d. Mäusetyphusvaccination etc.

den Zusatz von Immunserum nicht ohne weiteres die Antigenwirkung aufhebt. Ich erinnere nur daran, dass Behring (4) durch den Zusatz von Antitoxin Tetanus- und Diphtherietoxin derart modificiren konnte, dass selbst die höchstempfänglichen Meerschweinchen gegen unverändertes Toxin immunisirt werden konnten, während dies nicht erreichbar ist, wenn man mil kleinen Dosen unveränderten Toxins arbeitet.

\section{Literatur.}

1) Citron, Die Immunisirung gegen die Bakterien der Hogcholera (Schweinepest) mit Hülfe von Bakterienextracten. Ein Beitrag zur Aggressinfrage. Zeitschr. f. Hygiene u. Infectionskrankh. 1906. Bd. 53.

2) Wassermann, Ostertag und Citron, Veber das gegenseitige immunisatorische Verhalten des Löffler'schen Mäusetyphusbacillus und der Schweinepestbacillen. Ebendas. 1906. Bd. 52.

3) Citron, Experimentelle Beiträge zur Beurtheilung der Hogcholeragruppe. Ebendas. 1906. Bd. 53.

4) v. Behring, Algemeine Therapie der Infectionskrankheiten. S. 1093. 